\title{
Descemet Membrane Endothelial Keratoplasty
} versus Descemet Stripping Automated Keratoplasty - Outcome of One Single Surgeon's
More Than 200 Initial Consecutive Cases

This article was published in the following Dove Press journal: Clinical Ophthalmology

\author{
Christina Jansen' \\ Madeleine Zetterberg ${ }^{1,2}$ \\ 'Department of Ophthalmology, Region \\ Västra Götaland, Sahlgrenska University \\ Hospital, Mölndal, Sweden; ${ }^{2}$ Department \\ of Clinical Neuroscience, Institute of \\ Neuroscience and Physiology, \\ Sahlgrenska Academy, University of \\ Gothenburg, Gothenburg, Sweden
}

Purpose: To compare clinical outcome and complications of Descemet stripping automated keratoplasty (DSAEK) and Descemet membrane endothelial keratoplasty (DMEK).

Methods: This is a retrospective study of the first consecutive cases of DSAEK and DMEK performed by a single surgeon at a tertiary referral centre. Best-corrected visual acuity (BCVA), postoperative complications, rate of rebubbling and regraft were the main outcome measures.

Results: The study included 241 eyes, 116 subjected to DSAEK and 125 to DMEK. Fuchs endothelial dystrophy (FED) was the predominant diagnosis in both groups. Mean BCVA at all follow-ups up to 2 years was in favour of DMEK. Median BCVA (decimal) at 1 year was 0.4 (0.13-0.60; interquartile range) for the DSAEK and 0.8 (0.6-1.0) for the DMEK group, $\mathrm{p}<0.001$. Preoperative BCVA in the DSAEK group was lower than in DMEK. There was no significant difference in visual improvement between groups at 1 year postoperatively. The most common postoperative complication in both groups was a pupillary block with high intraocular pressure, $27 \%$ and $34 \%$ respectively. This was not affected by the presence of an iridectomy/iridotomy. In the DMEK group, gas provided significantly better adherence than air $(p=0.020)$. Rebubbling for partial/total detachment was performed in $7 \%$ (DSAEK) and $11 \%$ (DMEK) of cases, $p=0.361$. Regraft within 2 years was performed in $13 \%$ of eyes in the DSAEK and $17 \%$ in the DMEK group, $\mathrm{p}=0.450$. No case of graft rejection occurred.

Conclusion: Both DSAEK and DMEK provide overall satisfying outcome and the two techniques do not differ significantly in postoperative pupillary block, detachment rate, early graft failure or graft rejection. However, differences at baseline may have influenced or obscured potential differences. In DMEK procedures, gas seems to facilitate early graft adherence.

Keywords: corneal endothelial transplantation, Descemet membrane endothelial keratoplasty, Descemet stripping automated keratoplasty, regraft, rejection, visual outcome

\section{Introduction}

Until the last years of the last century, penetrating keratoplasty (PK) was the only way to surgically treat endothelial dysfunction. Since then, there has been a major change of scene. During the last two decades, endothelial keratoplasty (EK) has replaced $\mathrm{PK}$ as the standard surgical treatment of endothelial dysfunction. Descemet stripping endothelial keratoplasty (DSAEK) was the first EK technique
Correspondence: Christina Jansen

Department of Ophthalmology, Mölndal,

SE-43। 80, Sweden

Tel +46313421000

Fax +46 31 4I 2904

Email christina.jansen@vgregion.se
Clinical Ophthalmology 2021:15 909-921

909 
to become adopted by a larger number of corneal surgeons. Several studies have compared DSAEK to PK. Besides the obvious advantages of elimination of sutureinduced complications and late wound dehiscence, there may be better long-term best-corrected visual acuity (BCVA), less change in refractive power, less induced astigmatism, faster visual rehabilitation and lesser demand of postoperative aftercare with $\mathrm{EK}^{1-4}$ Since Descemet membrane endothelial keratoplasty (DMEK) was described by Melles et al in 2006 this method has gained popularity and is used by a steadily increasing number of surgeons. $^{5}$ Its advocates claim an even faster visual recovery $^{6}$ and better visual outcome than with DSAEK. ${ }^{6-13}$ However, all reports are not consistent. A recent Cochrane systematic review found only lowcertainty evidence for better BCVA with DMEK compared to DSAEK. ${ }^{14}$ There are reports of a higher rate of rebubbling (repeated injection of air/gas in the anterior chamber (AC) to reattach the graft to recipient stroma) in DMEK compared to DSAEK. ${ }^{6,7}$

In 2010, DSAEK was introduced in our clinic (Department of Ophthalmology at Sahlgrenska University hospital, Gothenburg/Mölndal) and soon it replaced PK in cases of corneal endothelium dysfunction. In 2013, we started performing DMEK as an alternative EK and in 2015 it replaced DSAEK as the standard method for EK in our clinic. This study aimed to compare the two surgical methods in terms of visual outcome, complications and graft survival and also to compare the learning curves for DSAEK and DMEK.

\section{Materials and Methods}

The study gained approval from the local Ethical Committee at the University of Gothenburg and adhered to the Declaration of Helsinki. Since this was a retrospective study, written consent from the study participants was not required, as deemed by the Ethical Committee. Patient data confidentiality was fully ensured at all times, as stated in the permission approved by the Ethical Committee. Data were retrieved from medical records of all consecutive cases of EK performed until the time of analysis, 241 eyes in total. All procedures were performed by one corneal surgeon (C.J.) between September 2011 and August 2017, including 116 cases of DSAEK from the surgeon's first case in September 2011 and 125 cases of DMEK from the same surgeon's first case in September 2013. The records were searched for data on age, sex, primary indication, comorbidity, previous ocular surgery, preoperative BCVA, preoperative YAG-iridotomy, anaesthesia, intraoperative complications, air- or gas-fill, high intraocular pressure (IOP) postoperatively the first 24 hours, air/gas trapped under iris, air/gas tap, transplant attachment, postoperative BCVA, rebubbling, and regraft within 2 years.

\section{Surgical Procedure - General Aspects}

The grafts were provided by the local eye bank at Sahlgrenska University hospital, Gothenburg/Mölndal. Before accepted for transplantation, the grafts were tested negative for hepatitis B and C, HIV, syphilis, had negative cultures for bacteria and fungi and had an endothelial cell count of $>2000$ cells $/ \mathrm{mm} 2$. The grafts were stored in a minimal essential corneal organ culture medium (MEM, Biochrome, Germany) for a maximum of 30 days after harvesting. The majority of the procedures were performed under topical anaesthesia. At the beginning of the study period, DSAEK was most often performed under general anaesthesia, being the standard anaesthesia for PK and thus preferred during the introduction of EK. Gradually there was a transition to topical anaesthesia with Tetracaine $1 \%$, three drops with 1-minute interval, as a routine for DSAEK as well as DMEK later on. At the end of the study period, there was a transition to combined topical and intracameral anaesthesia with tetracaine drops supplemented with intracameral injection of $0.3 \mathrm{~mL}$ Xylocaine $10 \mathrm{mg} / \mathrm{mL}$. In both groups, miosis was induced preoperatively by instilling eye drops pilocarpine $4 \%$ twice with 5-minute interval.

\section{Surgical Procedure - DSAEK}

For DSAEK surgery, preoperative iridotomy was not performed as a routine. The graft was prepared immediately prior to surgery by the surgeon. The graft thickness after epithelial removal was measured with pachymetry and the choice of cutting head customized aiming for a remaining graft thickness of 100-130 $\mu \mathrm{m}$. The graft was cut using a microkeratome (3095, Gebauer SLc, Germany), after which it was trephined using a standard $7.75 \mathrm{~mm}$ vacuum donor cornea punch (Baron, USA). The patient was prepared with an anterior chamber (AC) maintainer stabilizing the $\mathrm{AC}$ by continuous irrigation of balanced saline solution (BSS). A circle of $8 \mathrm{~mm}$ in diameter was marked on the corneal surface. A temporal $2.75 \mathrm{~mm}$ main incision at 9 o'clock (right eye, 3 o'clock left eye) and one $1.0 \mathrm{~mm}$ keratocentesis at one clock step clockwise (right eye, anticlockwise in left eye) of the main incision was made. 
A descemetorhexis corresponding to the $8 \mathrm{~mm}$ marking on the surface was made on the endothelium using a reversed hook, Price hook (Moria, France) and the Descemet membrane (DM) and endothelium was removed using a 90degree stripper. The main incision was then widened to $4 \mathrm{~mm}$. The graft was introduced to the $\mathrm{AC}$ using a Busin spatula (Moria, France) and placement forceps (Coronet, Australia). The graft was positioned against the recipient stroma by injecting filtered air under the graft through a visco canalostomy cannula (Eagle labs, USA) and the graft centred, if needed, by stroking a cannula on the corneal surface. The main incision was sutured using a 10-0 Vicryl suture. Cefuroxime $1 \mathrm{mg}$ was injected into the AC. At the end of surgery, there was a 70/30 air/fluid fill in the AC. The patient was kept in a supine position for 2 hours. The eye was then examined and in the event of air trapped under iris or high IOP (pupillary block), an air tap was performed.

\section{Surgical Procedure - DMEK}

At the beginning of the study period, iridotomies were not performed. This was later changed to routinely performing two peripheral iridotomies with Neodymium: Yttrium Aluminium Garnet-(Nd: YAG)-laser, one inferiorly and one superiorly, prior to surgery. The day before surgery the transplant was "pre-cut" in the eye bank by the eye bank technicians. The endothelium was stained for a few seconds with $0.055 \%$ Monoblue (Arcadophta, France) and the DM and endothelium removed from the stroma. A $7.75 \mathrm{~mm}$ trephination of the endothelial graft was made with a punch (Moria, France). The pre-cut graft was stored in MEM until surgery.

Topical anaesthesia (or, in the latest cases, combined topical and intracameral anaesthesia) was obtained as described earlier. An 8-mm circular mark centred on the corneal surface was made. A temporal $2.75 \mathrm{~mm}$ main incision at 9 o'clock (right eye, 3 o'clock left eye) and two 23G keratocenteses at one clock hour on either side of the main incision were made. The AC was filled with air. A descemetorhexis corresponding to the $8 \mathrm{~mm}$ marking on the surface was made on the endothelium using a reversed hook, Price hook (Moria, France) and the Descemet membrane (DM) and endothelium were removed using a 90degree stripper. Air was then replaced with BSS. The graft was stained with Monoblue $0.055 \%$ (Arcadophta, France) for 2 minutes and then injected into the AC through a Geuder glass injector (Corneagen, USA). The graft was unfolded endothelial side down and centred using a combination of fluid waves and fluctuations in AC depth. Filtered air (for the first 37 DMEK cases) or 20\% sulfur hexafluoride (SF6), gas (for the remaining cases) was then injected under the graft, positioning it to the recipient stroma. A complete gas fill and slightly raised pressure were maintained for 7 minutes before the amount of gas was adjusted to approximately $80 \%$ gas fill and normal intraocular pressure. The patient was kept in the strict supine position for 2 hours. The eye was then examined and in the event of gas trapped under iris or high intraocular pressure (IOP), a gas tap was made. The patient was recommended mostly supine position for the rest of the day.

\section{Postoperative Care - General Aspects}

Postoperative medication included topical antibiotics, levofloxacin $5 \mathrm{mg} / \mathrm{mL}, 6$ times daily for 1 week and topical steroids, dexamethasone $1 \mathrm{mg} / \mathrm{mL}, 6$ times daily the first week and then tapered over 7 months. Postoperative follow-up was the same for both groups; patients were examined on day 1,1 week and 1, 3, 6, 12 and 24 months after surgery. BCVA, graft attachment, and IOP were evaluated.

\section{Definitions of Outcome and Complications}

Graft rejection was defined as an incident with keratic precipitates and/or flare in the $\mathrm{AC}$, with or without corneal edema, whereas the definition of graft failure was the loss of (or inability to achieve) transparency of the central cornea for more than 3 months. Iatrogenic failure was defined as preoperative inability to achieve a completely unfolded and correctly oriented graft. High postoperative IOP was defined as an IOP of $30 \mathrm{mmHg}$ or more (as measured with rebound tonometry or Goldmann applanation tonometry), or (in some cases of pupillary block with a patient in discomfort and/or pain) by digital palpation.

\section{Statistical Procedures}

For evaluation of visual outcome, eyes with previous corneal transplantation or other ocular morbidity were excluded from the analysis. Visual acuity is presented in the logarithm of the minimum angle of resolution (logMAR) and where suitable also in decimal. For arithmetic procedures and statistical analysis, it was converted to $\log$ MAR. Mean with standard deviation (SD) and median with interquartile range (IQR) or minimum-maximum range are given as appropriate. For significance testing, unpaired Student's $t$-test was used and for calculation of 
Table I Demographic Description

\begin{tabular}{|c|c|c|c|}
\hline \multirow[t]{2}{*}{ Parameter } & \multirow{2}{*}{$\begin{array}{c}\text { DSAEK Group } \\
\mathrm{N}=1 \mathrm{I} 6\end{array}$} & \multirow{2}{*}{$\begin{array}{c}\text { DMEK Group } \\
N=\mid 25\end{array}$} & \multirow[t]{2}{*}{ p-value } \\
\hline & & & \\
\hline \multicolumn{4}{|l|}{ Age, years } \\
\hline - Mean $\pm S D$ & $75.1 \pm 10.5$ & $72.8 \pm 10.3$ & $0.089^{b}$ \\
\hline - Median (range) & $76.0(47-92)$ & $72(4 \mid-95)$ & $0.054^{\mathrm{c}}$ \\
\hline \multicolumn{4}{|l|}{ Sex, n (\%) } \\
\hline - Men & $45(38.8)$ & $45(36.0)$ & $0.690^{d}$ \\
\hline - Women & $7 \mid(6 I .2)$ & $80(64.0)$ & \\
\hline \multicolumn{4}{|l|}{ Indication for corneal transplantation, n (\%) } \\
\hline - Primary endothelial failure & $69(59.5)$ & $102(81.6)$ & $<0.001^{\mathrm{e}}$ \\
\hline - Secondary endothelial failure & $28(24.1)$ & $9(7.2)$ & \\
\hline - Regraft & $19(16.4)$ & $14(\mid I .2)$ & \\
\hline \multicolumn{4}{|l|}{ Previous corneal transplantation, $\mathrm{n}(\%)$} \\
\hline - None & $97(83.6)$ & III (88.8) & $0.265^{\mathrm{e}}$ \\
\hline - Previous PK & $5(4.3)$ & I (0.8) & \\
\hline - Previous DSAEK & $6(5.2)$ & $6(4.8)$ & \\
\hline - Previous DMEK & $7(6.0)$ & $7(5.6)$ & \\
\hline - Both DSAEK and PK & I (0.9) & $0(0)$ & \\
\hline Previous cataract surgery, n (\%) & $99(85.3)$ & $107(85.6)$ & $1.000^{\mathrm{d}}$ \\
\hline \multicolumn{4}{|l|}{ Ocular comorbidity, n (\%) } \\
\hline - None other than corneal pathology & $75(64.7)$ & $91(73.4)$ & $0.210^{\mathrm{e}}$ \\
\hline • Glaucoma & $12(10.7)$ & $12(9.7)$ & \\
\hline - AMD & $14(12.5)$ & $9(7.3)$ & \\
\hline - Other & $21(18.8)$ & $16(12.9)$ & \\
\hline
\end{tabular}

Notes: ${ }^{a} \mathrm{~A}$ p-value $<0.05$ was considered statistically significant. ${ }^{\mathrm{b}}$ t-test for independent groups. 'Mann-Whitney U-test. ${ }^{\mathrm{d}}$ Fisher's exact test. ${ }^{\mathrm{e}}$ Pearson's Chi-square test. fSome eyes had more than one pathology.

Abbreviations: AMD, age-related macular degeneration; DMEK, Descemet membrane endothelial keratoplasty; DSAEK, Descemet stripping automated keratoplasty; PK, penetrating keratoplasty.

possible differences in BCVA improvement, paired $t$-test was performed. The latter was important for compensating for differences in BCVA between the DSAEK and the DMEK groups at baseline. Non-parametric test, ie Mann-Whitney U-test, was used for comparison of decimal BCVA between groups since this type of outcome data is not normally distributed. For proportions, Fisher's exact test or Pearson's Chi-square test were used. A p-value of $<0.05$ was considered statistically significant, except in Table 4, where a Bonferroni-correction for multiple comparisons was performed yielding a significance level of $0.007(0.05 / 7)$. SPSS, version 25.0 for Mac (SPSS Inc., Chicago, IL) was used as statistics software.

\section{Results}

\section{Demographics}

There were no significant differences in age or sex distribution between the DSAEK and the DMEK groups
(Table 1). The most common indication for surgery in both groups was primary endothelial failure, which with a few exceptions, represented Fuchs endothelial dystrophy. The majority of eyes in both groups were pseudophakic, had no ocular morbidity other than corneal and had not undergone previous corneal transplantation.

\section{Surgical Management and Complications}

The majority of surgeries in both groups were performed as in-house procedures (Table 2). In the DSAEK group, EK was combined with cataract surgery (phacoemulsification with intraocular lens) in 14 cases (12\%) while in the DMEK group there was one case $(0.8 \%)$ of combined surgery. Surgical management and intra-/postoperative complications are summarized in Table 2. The most common complication in both groups was a transient rise in IOP the first 24 hours after surgery. High IOP occurred in about one third of cases with no significant difference between groups $(\mathrm{p}=0.322$, 
Table 2 Surgical Procedure and Intra-/Postoperative Complications

\begin{tabular}{|c|c|c|c|}
\hline \multirow[t]{2}{*}{ Parameter } & \multirow{2}{*}{$\begin{array}{c}\text { DSAEK Group } \\
\mathrm{N}=116\end{array}$} & \multirow{2}{*}{$\begin{array}{c}\text { DMEK Group } \\
\mathrm{N}=125\end{array}$} & \multirow[t]{2}{*}{ p-value } \\
\hline & & & \\
\hline Anaesthesia, n (\%) & $n=1 \mid 3$ & $n=|2|$ & \\
\hline - Topical only & $55(48.7)$ & $110(90.9)$ & $<0.001^{b}$ \\
\hline - Retrobulbar & $4(3.5)$ & I (0.8) & \\
\hline - General anaesthesia & $54(47.8)$ & $10(8.3)$ & \\
\hline Outpatient/inhouse procedure, n (\%) & $n=115$ & $n=124$ & \\
\hline - Outpatient & $6(5.2)$ & $12(9.7)$ & $0.226^{\mathrm{c}}$ \\
\hline - Inhouse & $109(94.8)$ & $112(90.3)$ & \\
\hline \multirow[t]{2}{*}{ Combined with phacoemulsification, n (\%) } & $\mathrm{n}=115$ & $n=124$ & \\
\hline & $14(12.2)$ & $\mathrm{I}(0.8)$ & $<0.001^{\mathrm{c}}$ \\
\hline Air or gas, $n(\%)$ & $\mathrm{n}=115$ & $n=122$ & \\
\hline - Air & $115(100)$ & $39(32.0)$ & $<0.001^{\mathrm{c}}$ \\
\hline - Gas & $0(0)$ & $83(68.0)$ & \\
\hline \multirow[t]{2}{*}{ Preoperative iridotomy, n (\%) } & $n=116$ & $n=124$ & \\
\hline & $9(7.8)$ & $76(61.3)$ & $<0.001^{\mathrm{c}}$ \\
\hline \multirow[t]{2}{*}{ Postoperative IOP >30 mmHg, n (\%) } & $n=113$ & $n=119$ & \\
\hline & 31 (27.4) & $40(33.6)$ & $0.322^{c}$ \\
\hline \multirow[t]{2}{*}{ Air/gas under iris, $n$ (\%) } & $n=101$ & $n=119$ & \\
\hline & $23(22.8)$ & $37(31.1)$ & $0.176^{\mathrm{c}}$ \\
\hline \multirow[t]{2}{*}{ Air/gas tap postoperatively, n (\%) } & $n=112$ & $n=124$ & \\
\hline & $45(40.2)$ & $49(39.5)$ & $1.000^{c}$ \\
\hline \multirow[t]{2}{*}{ Rebubbling, n (\%) } & $n=113$ & $n=116$ & \\
\hline & $8(7.1)$ & $13(\mid 1.2)$ & $0.36 \mathrm{I}^{\mathrm{c}}$ \\
\hline \multicolumn{4}{|l|}{ Transplant adherent postoperatively, $\mathrm{n}(\%)^{\mathrm{d}}$} \\
\hline - Day I & $109(95.6)$ & II $3(94.2)$ & $0.769^{c}$ \\
\hline - After I week & $107(94.7)$ & $110(91.7)$ & $0.442^{c}$ \\
\hline - After I month & $93(97.9)$ & $97(93.3)$ & $0.174^{c}$ \\
\hline \multirow[t]{2}{*}{ Retransplantation within 2 years, n (\%) } & $\mathrm{n}=109$ & $\mathrm{n}=110$ & \\
\hline & $14(12.8)$ & $19(17.3)$ & $0.450^{c}$ \\
\hline
\end{tabular}

Notes: ${ }^{a} \mathrm{~A}$ p-value $<0.05$ was considered statistically significant. ${ }^{\mathrm{b}}$ Pearson's Chi-square test. ${ }^{\mathrm{C}}$ Fisher's exact test. ${ }^{\mathrm{d}}$ Denotes transplant completely and partially adherent. Abbreviations: DMEK, Descemet membrane endothelial keratoplasty; DSAEK, Descemet stripping automated keratoplasty; IOP, intraocular pressure.

Table 2). There was no significant difference between the groups in terms of the presence of air/gas under the iris (pupillary block). Air/gas tap was performed postoperatively in $40 \%$ of cases in both the DSAEK and DMEK groups. There was no significant difference in the proportion of high IOP $(>30 \mathrm{mmHg})$ between those who had an iridotomy preoperatively $(\mathrm{n}=82)$ and those who did not $(\mathrm{n}=150)$, $\mathrm{p}=0.768$, see Table 3 .

\section{Graft Adherence and Retransplantation}

Graft adherence did not differ significantly between the DSAEK and DMEK groups at any follow-up interval
(Table 2). In a subgroup analysis of the DMEK group, patients treated with gas had significantly better graft adherence at 1 week compared to DMEK patients treated with air, $\mathrm{p}=0.020$ (Table 3 ). Since all DSAEK procedures were performed with air, a comparison was also made with those DMEK eyes that were treated with air, demonstrating significantly better graft adherence in the DSAEK than in the DMEK group; 95\% versus 82\%, $\mathrm{p}=0.021$ (Table 3). A detached or not sufficiently adherent graft was treated with reinjection of air or gas, ie rebubbling. There was no significant difference in rebubbling rate between the DSAEK and DMEK groups $(\mathrm{p}=0.361$, Table 2$)$ and no 
Table 3 Subgroup Analysis of Outcome in DSAEK and DMEK Patients

\begin{tabular}{|c|c|c|c|}
\hline Parameter & Air & Gas & p-value ${ }^{a}$ \\
\hline Graft adherent Ist week, both DSAEK and DMEK, $\mathrm{n}(\%)^{\mathrm{c}}$ & $\begin{array}{c}n=149 \\
136(91.3)\end{array}$ & $\begin{array}{c}n=82 \\
79(96.3)\end{array}$ & $0.335^{b}$ \\
\hline Graft adherent Ist week, DMEK only, n (\%) $^{c}$ & $\begin{array}{c}n=37 \\
30(81.1)\end{array}$ & $\begin{array}{c}n=82 \\
79(96.3)\end{array}$ & $0.020^{\mathrm{b}}$ \\
\hline Rebubbling, both DSAEK and DMEK, $\mathrm{n}(\%)$ & $\begin{array}{c}n=149 \\
14(9.4)\end{array}$ & $\begin{array}{c}n=77 \\
7(9.1)\end{array}$ & $0.900^{\mathrm{b}}$ \\
\hline Rebubbling, DMEK only, n (\%) & $\begin{array}{c}n=37 \\
6(16.2)\end{array}$ & $\begin{array}{c}n=77 \\
7(9.1)\end{array}$ & $0.465^{\mathrm{b}}$ \\
\hline & DSAEK Group & DMEK Group & \\
\hline Graft adherent Ist week, air only, n (\%) ${ }^{c}$ & $\begin{array}{c}n=115 \\
109(94.8)\end{array}$ & $\begin{array}{c}n=39 \\
32(82.1)\end{array}$ & $0.021^{\mathrm{b}}$ \\
\hline Rebubbling, air only, n (\%) & $\begin{array}{l}n=112 \\
8(7.1)\end{array}$ & $\begin{array}{c}n=37 \\
6(16.2)\end{array}$ & $0.113^{b}$ \\
\hline & No Iridotomy & Iridotomy & \\
\hline IOP >30 mmHg, n (\%), DSAEK and DMEK & $\begin{array}{c}n=150 \\
47(31.3)\end{array}$ & $\begin{array}{c}n=82 \\
24(29.3)\end{array}$ & $0.768^{\mathrm{b}}$ \\
\hline
\end{tabular}

Notes: ${ }^{a} \mathrm{~A}$ p-value $<0.05$ was considered statistically significant. ${ }^{\mathrm{b}} \mathrm{Chi}$-square test. ${ }^{\mathrm{c}}$ Denotes transplant completely and partially adherent.

Abbreviations: DMEK, Descemet membrane endothelial keratoplasty; DSAEK, Descemet stripping automated keratoplasty; IOP, intraocular pressure.

significant difference between DMEK cases in a subgroup analysis comparing air to gas $(\mathrm{p}=0.465$, Table 3$)$. Neither was there any significant difference in rebubbling rate between DSAEK eyes or DMEK cases treated with air $(p=0.113$, Table 3$)$. The incidence of retransplantation within 2 years did not differ significantly between the DSAEK and the DMEK groups; 14 (13\%) vs 19 (17\%, $\mathrm{p}=0.450$; Table 2). In the DMEK group, there were three cases with intraoperative difficulties in unfolding or positioning of the graft, resulting in immediate regraft and six additional cases in which the graft was left in the AC until the regrafting surgery. These iatrogenic failures are included in the regraft group. There was no case of graft rejection in either group during the follow-up period.

\section{Visual Outcome}

Eyes with another ocular morbidity than endothelial failure or with previous transplantation were not included in the analysis of visual outcome. The visual outcome of DSAEK and DMEK surgery for up to 2 years is shown in Table 4. Mean preoperative BCVA in the DMEK group was $0.65 \log$ MAR and median BCVA 0.3 (decimal; interquartile range [IQR] 0.2 to 0.5 ), which was significantly better than preoperative BCVA in the DSAEK group; mean $1.1 \operatorname{logMAR}$, median
0.1 (IQR 0.02-0.28; $\mathrm{p}<0.001$ ). With the exception of a slight decrease in BCVA at 1 week in the DMEK group, from that point on both groups showed steady improvement in visual acuity up to 1 year after surgery with significantly better BCVA in the DMEK group at every follow-up point. In Figure 1, BCVA pre- and 1 year postoperatively is shown in $\log$ MAR as scatter plots for DSAEK and DMEK groups separately. At the last follow-up at 2 years, the mean BCVA in the DSAEK group was $0.47 \log$ MAR and the median BCVA was 0.5 (IQR 0.3-0.65). In the DMEK group, mean BCVA was 0.18 logMAR and median BCVA 0.75 (IQR 0.6-1.0), $\mathrm{p}=0.029$ (unpaired $t$-test $\log \mathrm{MAR}$ ) and $\mathrm{p}=0.001 \quad$ (Mann-Whitney U-test) respectively. The improvement in BCVA, ie postoperative BCVA compared to BCVA prior to surgery did not differ significantly between the DSAEK and the DMEK group at any time point, see Table 4 and Figure 2. When looking at proportions attaining a certain level of visual acuity, 93\% of cases in the DMEK group attained a BCVA of $\leq 0.3$ (logMAR), $55 \%$ reached $\leq 0.1$ and $28 \%$ had a BCVA of $\leq 0.0$ one year after surgery (Table 5 ). For patients in the DSAEK group, corresponding numbers were $43 \%, 7 \%$ and $2 \%$, a highly significant difference $(p<0.001)$. When excluding patients who had 
Table 4 Visual Outcome in DSAEK and DMEK Patients

\begin{tabular}{|c|c|c|c|}
\hline \multirow[t]{2}{*}{ Parameter } & \multirow{2}{*}{$\begin{array}{c}\text { DSAEK Group } \\
\qquad N=61^{a}\end{array}$} & \multirow{2}{*}{$\begin{array}{c}\text { DMEK Group } \\
\mathbf{N}=80^{\mathrm{a}}\end{array}$} & \multirow[t]{2}{*}{ p-value } \\
\hline & & & \\
\hline BCVA, preoperatively & $\mathrm{n}=65$ & $n=80$ & \\
\hline - Mean $\pm S D$, unpaired, logMAR & $1.10 \pm 0.57$ & $0.65 \pm 0.44$ & $<0.001^{c}$ \\
\hline - Mean士SD, paired, logMAR & NA & NA & NA \\
\hline - Median (IQR), decimal & $0.10(0.02-0.28)$ & $0.30(0.20-0.50)$ & $<0.001^{d}$ \\
\hline - Range, decimal & $0.01-0.65$ & $0.00-0.90$ & \\
\hline BCVA, I week postoperatively & $\mathrm{n}=57$ & $\mathrm{n}=77$ & \\
\hline - Mean $\pm S D$, unpaired, logMAR & $1.10 \pm 0.44$ & $0.74 \pm 0.53$ & $<0.001^{\mathrm{c}}$ \\
\hline - Mean $\pm S D$, paired ${ }^{\mathrm{e}}$, logMAR & $0.04 \pm 0.58$ & $0.12 \pm 0.57$ & $0.459^{c}$ \\
\hline - Median (IQR), decimal & $0.10(0.05-0.16)$ & $0.20(0.12-0.45)$ & $<0.001^{d}$ \\
\hline - Range, decimal & $0.01-0.5$ & $0.01-1.0$ & \\
\hline BCVA, I month postoperatively & $n=5$ I & $n=68$ & \\
\hline - Mean $\pm S D$, unpaired, logMAR & $0.80 \pm 0.35$ & $0.46 \pm 0.42$ & $<0.00 I^{c}$ \\
\hline - Mean $\pm S D$, paired ${ }^{\mathrm{e}}$, logMAR & $-0.28 \pm 0.52$ & $-0.17 \pm 0.51$ & $0.27 I^{c}$ \\
\hline - Median (IQR), decimal & $0.16(0.1-0.30)$ & $0.45(0.25-0.70)$ & $<0.00 \mathrm{I}^{\mathrm{d}}$ \\
\hline - Range, decimal & $0.01-0.65$ & $0.01-1.0$ & \\
\hline BCVA, 3 months postoperatively & $n=31$ & $n=4 I$ & \\
\hline - Mean $\pm S D$, unpaired, logMAR & $0.68 \pm 0.35$ & $0.40 \pm 0.43$ & $0.005^{c}$ \\
\hline - Mean $\pm S D$, paired ${ }^{e}, \log M A R$ & $-0.39 \pm 0.48$ & $-0.21 \pm 0.33$ & $0.100^{c}$ \\
\hline - Median (IQR), decimal & $0.25(0.13-0.40)$ & $0.50(0.40-0.68)$ & $<0.001^{d}$ \\
\hline - Range, decimal & $0.03-0.60$ & $0.01-1.0$ & \\
\hline BCVA, 6 months postoperatively & $n=40$ & $\mathrm{n}=48$ & \\
\hline - Mean $\pm S D$, unpaired, logMAR & $0.60 \pm 0.34$ & $0.24 \pm 0.32$ & $<0.001^{c}$ \\
\hline - Mean $\pm S D$, paired ${ }^{\mathrm{e}}$, logMAR & $-0.5 I \pm 0.52$ & $-0.46 \pm 0.42$ & $0.623^{c}$ \\
\hline - Median (IQR), decimal & $0.30(0.14-0.50)$ & $0.65(0.50-0.80)$ & $<0.00 I^{d}$ \\
\hline - Range, decimal & $0.03-0.80$ & $0.0-1.0$ & \\
\hline BCVA, I year postoperatively & $n=42$ & $n=40$ & \\
\hline - Mean $\pm S D$, unpaired, logMAR & $0.57 \pm 0.45$ & $0.14 \pm 0.12$ & $<0.001^{c}$ \\
\hline - Mean $\pm S D$, paired ${ }^{e}, \log M A R$ & $-0.50 \pm 0.49$ & $-0.38 \pm 0.25$ & $0.088^{c}$ \\
\hline - Median (IQR), decimal & $0.40(0.13-0.60)$ & $0.80(0.61-1.0)$ & $<0.00 \mathrm{I}^{\mathrm{d}}$ \\
\hline - Range, decimal & $0.01-1.0$ & $0.0-1.0$ & \\
\hline BCVA, 2 years postoperatively & $n=31$ & $n=18$ & \\
\hline - Mean $\pm S D$, unpaired, logMAR & $0.47 \pm 0.54$ & $0.18 \pm 0.24$ & $0.029^{c}$ \\
\hline - Mean $\pm S D$, paired ${ }^{\mathrm{e}}, \log M A R$ & $-0.48 \pm 0.53$ & $-0.40 \pm 0.24$ & $0.579^{c}$ \\
\hline - Median (IQR), decimal & $0.5(0.30-0.65)$ & $0.75(0.58-1.0)$ & $0.001^{d}$ \\
\hline - Range, decimal & $0.01-1.0$ & $0.10-1.0$ & \\
\hline
\end{tabular}

Notes: ${ }^{a}$ Only eyes without previous corneal transplantation and without other ocular comorbidity except for previous cataract surgery were included in analysis. ${ }^{\mathrm{b}} \mathrm{A}$ p-value $<0.007$ was considered statistically significant. This level of significance was derived after Bonferroni-correction for multiple comparisons; $0.05 / 7=0.007$. ${ }^{c} t$-test for independent groups. 'Mann-Whitney U-test. ${ }^{\mathrm{e}}$ Mean difference between postoperative and preoperative BCVA.

Abbreviations: BCVA, best-corrected visual acuity; DMEK, Descemet membrane endothelial keratoplasty; DSAEK, Descemet stripping automated keratoplasty; IQR, interquartile range.

a retransplantation during the follow-up period, the proportion of patients with a BCVA of $\leq 0.1$ was almost unaltered; $56 \%$ of DMEK and $8 \%$ of DSAEK cases attained this level of BCVA. However, the mean improvement in BCVA did not differ significantly between groups; $-0.49 \pm 0.47$ in the DSAEK group and
$-0.39 \pm 0.26$ in the DMEK group (logMAR; $\mathrm{p}=0.259$ ). A subgroup analysis of the DMEK patients at 1-year follow-up showed no significant differences between eyes with air $(n=10)$ or gas $(n=28 ; p=0.846)$, nor was there any difference when comparing phakic $(n=25)$ or pseudophakic $(\mathrm{n}=105)$ DMEK eyes, $\mathrm{p}=0.149$. 


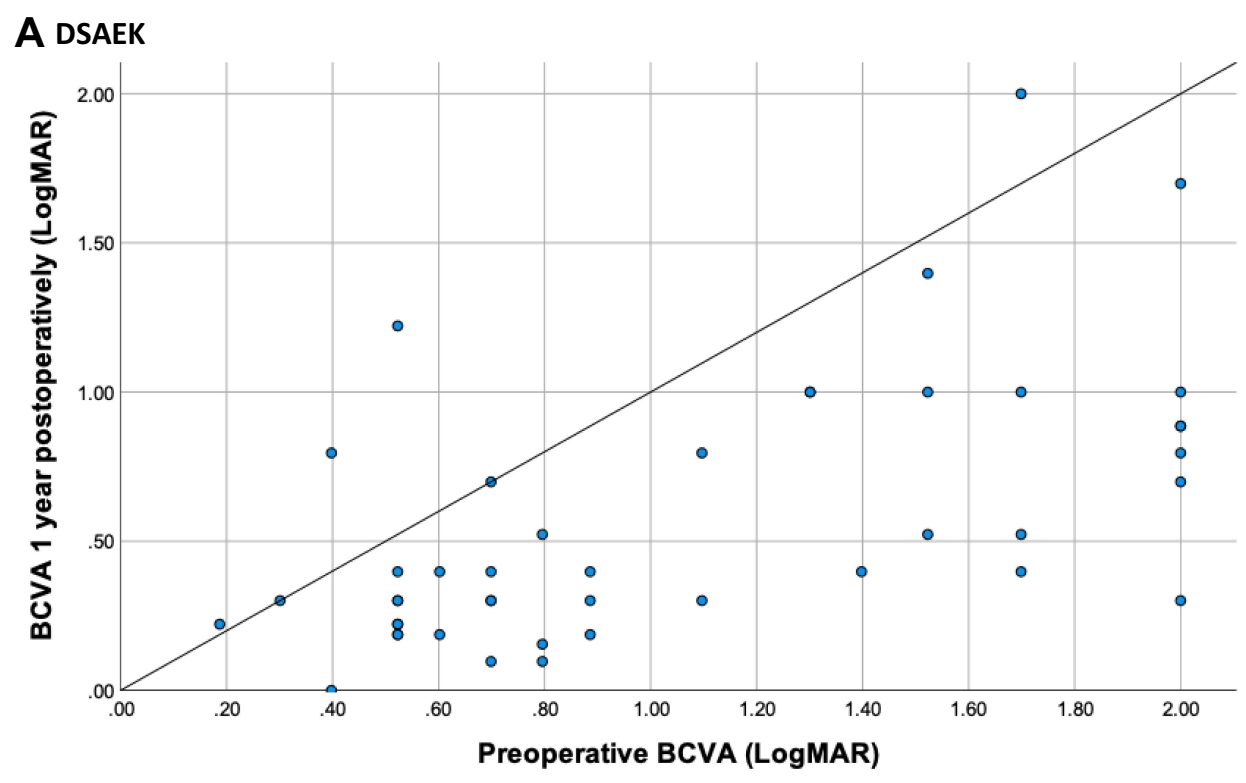

B DMEK

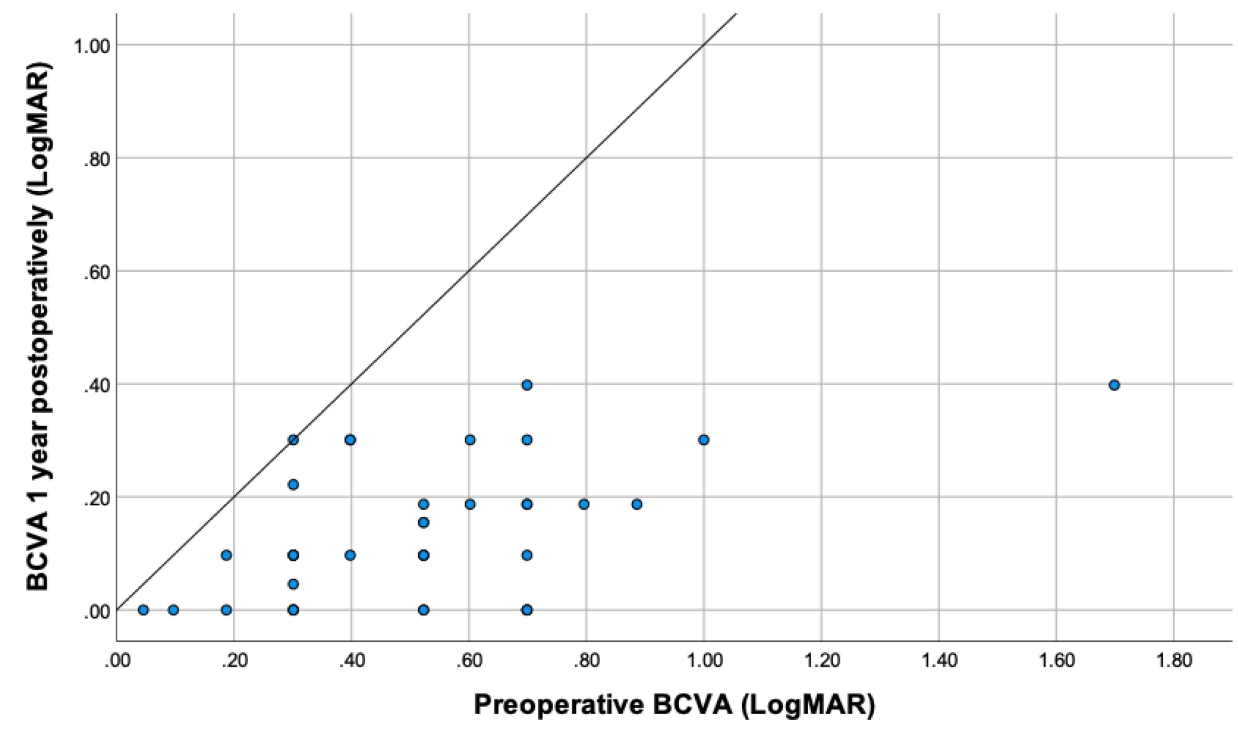

Figure I Scatter plots showing best-corrected visual acuity (BCVA) in LogMAR of the DSAEK (A) and DMEK (B) groups, respectively. Preoperative BCVA is shown on $x$-axis and postoperative BCVA on the $y$-axis. Marks below the line represent cases with postoperative improvement in BCVA whereas marks above the line represent worsening of BCVA after surgery.

\section{Learning Curve}

The outcome of the first 30 cases of each surgical technique was compared to the last 30 included cases, in order to investigate whether there was any sign of a learning curve (Table 6). There were no statistically significant differences between the first 30 and the most recent 30 cases with either DSAEK or DMEK for any of the outcome parameters rebubbling, regraft within 2 years or BCVA at 1 year.

\section{Discussion}

\section{Visual Outcome}

The DMEK patients had better BCVA than the DSAEK patients at all follow-up intervals. This is consistent with previous studies comparing DSAEK to DMEK when comparing postoperative BCVA. ${ }^{11}$ However, when looking at the improvement in BCVA, ie the postoperative BCVA compared to preoperative BCVA, no difference between 


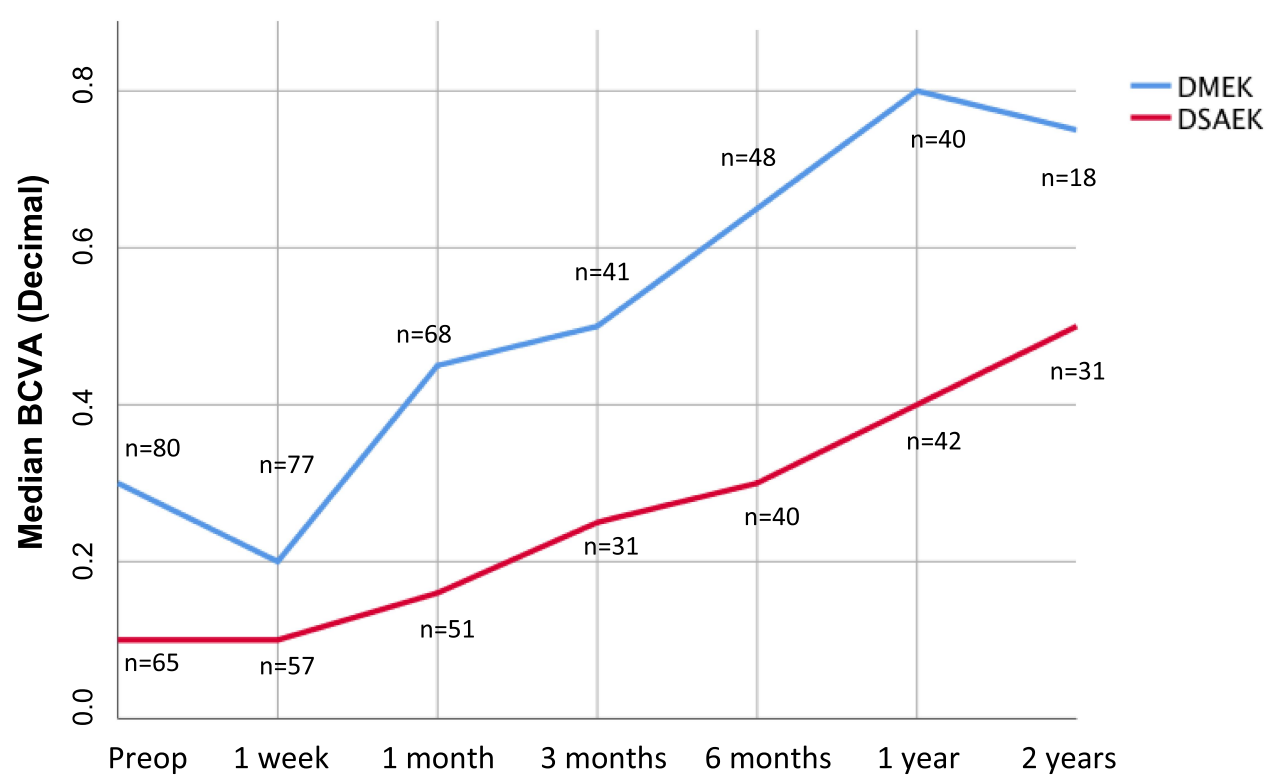

Figure 2 Median BCVA (decimal) is plotted over time showing a steadily improvement of BCVA for both the DSAEK and the DMEK groups. The number of cases in each group at every time point is given.

the groups was seen in the present data. It has been shown previously that very poor preoperative visual acuity (VA) has a negative effect on the possibility of attaining a good postoperative VA. ${ }^{15}$ This can probably be explained by the formation of subepithelial fibrosis in advanced and longstanding corneal oedema. ${ }^{16,17}$ In the present study, the most important demographic difference between the groups was that of the preoperative visual acuity, with DSAEK patients exhibiting lower BCVA preoperatively. This is an important limitation of the study but also reflects

Table 5 Visual Outcome as Proportions and Subgroup Analyses

\begin{tabular}{|c|c|c|c|}
\hline Parameter & DSAEK Group $N=42^{d}$ & DMEK Group $N=40^{d}$ & p-value ${ }^{a}$ \\
\hline $\begin{array}{l}\text { BCVA (LogMAR), I year postop, n (\%) } \\
\text { - Proportion with BCVA } \leq 0.0 \\
\text { - Proportion with BCVA } \leq 0.1 \\
\text { - Proportion with BCVA } \leq 0.3\end{array}$ & $\begin{array}{c}\text { I }(2.4) \\
3(7.1) \\
18(42.9)\end{array}$ & $\begin{array}{l}\text { II }(27.5) \\
22(55.0) \\
37(92.5)\end{array}$ & $\begin{array}{l}0.001^{\mathrm{b}} \\
<0.00 \mathrm{I}^{\mathrm{b}} \\
<0.00 \mathrm{I}^{\mathrm{b}}\end{array}$ \\
\hline $\begin{array}{l}\text { BCVA, I year postop, retransplant omitted } \\
\text { - Proportion with BCVA } \leq 0 . \text { I (LogMAR), n (\%) }\end{array}$ & $\begin{array}{c}\mathrm{n}=38 \\
3(7.9)\end{array}$ & $\begin{array}{c}n=34 \\
19(55.9)\end{array}$ & $<0.001^{b}$ \\
\hline $\begin{array}{l}\text { BCVA, I year postop, retransplant omitted } \\
\text { - Mean paired } \pm \text { SD, logMAR }\end{array}$ & $\begin{array}{c}n=38 \\
-0.49 \pm 0.47\end{array}$ & $\begin{array}{c}n=33 \\
-0.39 \pm 0.26\end{array}$ & $0.259^{c}$ \\
\hline & Air & Gas & \\
\hline $\begin{array}{l}\text { BCVA, I year postop, DMEK only } \\
\text { - Mean } \pm \text { SD, paired, logMAR }\end{array}$ & $\begin{array}{c}n=10 \\
-0.37 \pm 0.22\end{array}$ & $\begin{array}{c}n=28 \\
-0.38 \pm 0.27\end{array}$ & $0.846^{\mathrm{c}}$ \\
\hline & Phakic & Pseudophakic & \\
\hline $\begin{array}{l}\text { BCVA, I year postop, DMEK only } \\
\text { - Mean } \pm \text { SD, paired, logMAR }\end{array}$ & $\begin{array}{c}n=25 \\
-0.79 \pm 0.62\end{array}$ & $\begin{array}{c}n=105 \\
-1.00 \pm 0.84\end{array}$ & $0.149^{c}$ \\
\hline
\end{tabular}

Notes: ${ }^{\mathrm{a}} \mathrm{A} \mathrm{p}$-value $<0.05$ was considered statistically significant. ${ }^{\mathrm{b}}$ Fisher's exact test. ${ }^{\mathrm{C}}$ Independent samples $t$-test. ${ }^{\mathrm{d}}$ Only eyes without previous corneal transplantation and without other ocular comorbidity except for previous cataract surgery were included in analysis. ${ }^{\text {Patients }}$ who had a retransplantation during the follow-up period were omitted from analysis.

Abbreviations: BCVA, best-corrected visual acuity; DMEK, Descemet membrane endothelial keratoplasty; DSAEK, Descemet stripping automated keratoplasty; IQR, interquartile range. 
Table 6 Learning Curve in DSAEK and DMEK Patients

\begin{tabular}{|c|c|c|c|}
\hline Parameter & 30 First Cases & 30 Most Recent Cases & p-value ${ }^{a}$ \\
\hline Rebubbling, DSAEK only, n (\%) & $\begin{array}{c}n=29 \\
0(0.0)\end{array}$ & $\begin{array}{l}n=29 \\
I(3.4)\end{array}$ & $1.000^{\mathrm{b}}$ \\
\hline Retransplant within 2 years, DSAEK only, n (\%) & $\begin{array}{c}n=27 \\
3(I I . I)\end{array}$ & $\begin{array}{c}n=28 \\
5(17.9)\end{array}$ & $0.705^{b}$ \\
\hline $\begin{array}{l}\text { BCVA, I year postop, DSAEK only } \\
\text { - Mean paired } \pm \text { SD, logMAR }\end{array}$ & $\begin{array}{c}n=23 \\
-0.60 \pm 0.54\end{array}$ & $\begin{array}{c}n=14 \\
-0.64 \pm 0.67\end{array}$ & $0.844^{c}$ \\
\hline Rebubbling, DMEK only, n (\%) & $\begin{array}{c}n=28 \\
3(10.7)\end{array}$ & $\begin{array}{c}n=28 \\
5(17.9)\end{array}$ & $0.705^{b}$ \\
\hline Retransplant within 2 years, DMEK only, n (\%) & $\begin{array}{c}n=28 \\
7(25.0)\end{array}$ & $\begin{array}{c}n=25 \\
6(24.0)\end{array}$ & $1.000^{\mathrm{b}}$ \\
\hline $\begin{array}{l}\text { BCVA, I year postop, DMEK only } \\
\text { - Mean paired } \pm \text { SD, logMAR }\end{array}$ & $\begin{array}{c}n=12 \\
-0.76 \pm 0.60\end{array}$ & $\begin{array}{c}n=16 \\
-0.49 \pm 0.31\end{array}$ & $0.133^{c}$ \\
\hline
\end{tabular}

Notes: ${ }^{\mathrm{a} A} \mathrm{p}$-value $<0.05$ was considered statistically significant. ${ }^{\mathrm{b}}$ Fisher's exact test. 'Independent samples $t$-test. ${ }^{\mathrm{d}}$ Only eyes without previous corneal transplantation and without other ocular comorbidity except for previous cataract surgery were included in analysis.

Abbreviations: DMEK, Descemet membrane endothelial keratoplasty; DSAEK, Descemet stripping automated keratoplasty; IQR, interquartile range.

a real-world situation in the way the two techniques were introduced at the department. In the early years of DSAEK, there was a tendency to wait until later on in the progress of endothelial dystrophy, probably reflecting the experience of PK on FED. As we gradually grew accustomed to the faster recovery and better patient satisfaction with EK we now probably tend to perform keratoplasty at an earlier stage resulting in higher preoperative BCVA. A large proportion of the DSAEK cases are from these "early years", thus many cases entered surgery at a more advanced stage of the disease. When later transitioning from DSAEK to DMEK we tended to choose DMEK for the uncomplicated eyes and DSAEK for eyes with reduced corneal transparency, thereby selecting cases with poorer preoperative BCVA for DSAEK. There is also previous evidence that patients with pseudophakic bullous keratopathy (PBK) have poorer visual outcome than patients with Fuchs endothelial dystrophy after $\mathrm{PK}^{18}$ and the same is shown after EK. ${ }^{2}$ Although primary endothelial failure (endothelial dystrophy) was the most common indication in both groups, there was a higher proportion of patients with secondary endothelial failure (mostly PBK) in the DSAEK group. A limitation of the study is the lack of endothelial cell count; this was not a routine at the department at the time, and given the retrospective nature of the study, this data is missing.

Another limitation in the present study is the selection of patients remaining for follow-up. Cases with fast visual recovery and no complications were sometimes omitted from the follow-up, in contrast to complicated cases or dissatisfied patients. This is valid for both the DSAEK and DMEK groups, but since this way of postoperative management has increased in recent years, it probably has a greater effect on the outcome in the DMEK group. This may explain the fact that the DSAEK group continued to improve during the second year of follow-up, in contrast to the DMEK group (Figure 2). A study with prolonged follow-up would thus be interesting.

\section{Complications}

The most common complication in this study; raised IOP during the first postoperative hours, is probably related to a combination of factors; pupillary size, the amount of air/ gas left in the AC at the end of surgery and the fact that we do not routinely reduce the amount of air/gas in the AC postoperatively. Terry et al have described a routine with a smaller amount of gas and a free-floating bubble, reporting a very low incidence of pupillary block. ${ }^{19}$ Miosis might increase the risk of pupillary block. During the study period, the standard procedure was to induce miosis whereas other studies describe a strategy with pharmacologic mydriasis instead. We have since the study period changed our routine to topical mydriatics at the end of surgery and experience a decrease in the need for air/gas tap. Preoperatively, we routinely created a peripheral iridotomy by Nd: YAG-laser, while others have described performing a basal iridectomy intraoperatively. In the present study, it was shown that in our hands, a preoperative 
Nd: YAG iridotomy was ineffective as there was no difference in the incidence of postoperative high IOP between patients who had an iridotomy or not.

\section{Graft Adherence and Rebubbling}

The overall rebubbling rate of $8 \%$ shown here, is relatively low compared to previously published studies. ${ }^{13,20}$ This may partially be due to the fact that we fill the $\mathrm{AC}$ with more gas than, for example, Terry et al. ${ }^{19}$ In addition, we do not routinely let out any gas postoperatively unless signs of pupillary block. ${ }^{21}$ Air was replaced by gas fill (20\% SF6) for DMEK patients during the study period after experiencing a cluster of detachment episodes. Although there have been reports on endothelial toxicity from SF6, others have demonstrated equal loss of endothelial cells when using SF6 instead of air and with a significantly lower rate of rebubbling. ${ }^{22,23}$ However, the present study showed no statistically significant difference in rebubbling rates when comparing air fill to gas fill, but the rate of graft adherence at 1 week in the group treated with gas was higher. A randomized study to investigate which option is the most successful would be of interest.

Previous studies have shown a higher rebubbling rate for DMEK than for DSAEK. ${ }^{13}$ A Cochrane report from $2018^{14}$ also found that the need for rebubbling was more common with DMEK than DSAEK but with very low certainty of evidence. In the present study, there was no difference in the rebubbling rate between DSAEK and DMEK patients when considering all cases. However, when omitting DMEK cases treated with gas, only comparing DMEK with air and DSAEK eyes (all of which were treated with air), the present data demonstrated a significantly higher rate of adherence at 1 week for the DSAEK compared to the DMEK group. Caution should be applied when interpreting this finding, however, due to differences between the DSAEK and DMEK groups at baseline.

\section{Regraft}

The rate of regrafting in this cohort was relatively high compared to previously published reports ${ }^{4,24-26}$ The iatrogenic graft failures resulting from preoperative complications, such as difficulties in graft unfolding or positioning, are included as regrafts. Another factor that may explain the rate of graft failure in this data, is the use of precut tissue in all DMEK cases, something that has been suggested to have a negative influence on graft survival. ${ }^{27}$ There might also be a link between regrafts and a low incidence of rebubbling. In the case of a partially attached graft, there is always the choice either to do rebubbling immediately or to wait for spontaneous attachment. In some cases of late rebubbling the graft has formed irreversible folds, resulting in regrafting. The perfect timing for rebubbling has yet to be established.

\section{Learning Curve}

No evidence for a learning curve was evident in the present study for either of the surgical techniques. Since DSAEK was the first technique adapted by the surgeon, there was the advantage of the experience of the first 65 DSAEK cases when taking on the first DMEK case. However, the most challenging aspects of DMEK surgery are not the same as in DSAEK, and the effect of this experience on the learning curve for DMEK is probably limited. During the study period, gradually more complicated cases - both DSAEK and DMEK - were undertaken as the surgeon gained more experience. This may to some extent have masked the effect of a possible learning curve.

\section{Summary/Conclusion}

Both DSAEK and DMEK provide satisfying visual outcome and complication rate as demonstrated in the present study, including more than 200 eyes, even in the hands of an inexperienced surgeon. Although there was significantly better BCVA after DMEK than DSAEK, there was no significant difference in visual improvement which may be due to differences at baseline. There is a need for both prospective randomized trials and studies with longer follow-up, since the results from the present study indicate ongoing progress in BCVA even after 2 years. This study found that the rate of pupillary block was independent of the presence of a preoperative iridotomy, indicating that this precautious measure may be abandoned. The finding that SF6 gas provided better graft adherence at 1 week postoperatively than air in DMEK patients is interesting and warrants further investigation.

\section{Acknowledgments}

The study was financed by grants from the Swedish state under the agreement between the Swedish government and the county councils, the ALF-agreement (ALF-GBG -725041), Göteborg Medical Society, Dr Reinhard Marcuses Foundation, Konung Gustaf V: soch Drottning Victorias Frimurarestiftelse, Hjalmar Svensson Foundation, Greta Andersson Foundation, Herman 
Svensson Foundation, De Blindas Vänner and Kronprinsessan Margaretas Arbetsnämnd för Synskadade. Presented in part at the annual meeting of the Swedish Ophthalmological Society in Stockholm, Sweden, 9 Oct 2018.

\section{Disclosure}

None of the authors has a financial or proprietary interest in any material or method mentioned. $\mathrm{TB}$ and $\mathrm{AB}$ have received lecture fees and travel expenses from Allergan Inc. The authors report no other conflicts of interest in this work.

\section{References}

1. Melles GR. Posterior lamellar keratoplasty: DLEK to DSEK to DMEK. Cornea. 2006;25(8):879-881. doi:10.1097/01.ico.0000243962.60392.4f

2. Fuest M, Ang M, Htoon HM, Tan D, Mehta JS. Long-term visual outcomes comparing Descemet stripping automated endothelial keratoplasty and penetrating keratoplasty. Am $J$ Ophthalmol. 2017;182:62-71. doi:10.1016/j.ajo.2017.07.014

3. Greenrod EB, Jones MN, Kaye S, et al. Center and surgeon effect on outcomes of endothelial keratoplasty versus penetrating keratoplasty in the United Kingdom. Am J Ophthalmol. 2014;158(5):957-966. doi:10.1016/j.ajo.2014.07.037

4. van Rooij J, Lucas EH, Geerards AJ, Remeijer L, Wubbels R. Corneal transplantation for Fuchs endothelial dystrophy: a comparison of three surgical techniques concerning 10 year graft survival and visual function. PLoS One. 2018;13(10):e0203993. doi:10.1371/journal.pone.0203993

5. Melles GR, Ong TS, Ververs B, van der Wees J. Descemet membrane endothelial keratoplasty (DMEK). Cornea. 2006;25(8):987-990.

6. Tourtas T, Laaser K, Bachmann BO, Cursiefen C, Kruse FE. Descemet membrane endothelial keratoplasty versus descemet stripping automated endothelial keratoplasty. Am J Ophthalmol. 2012;153 (6):1082-1090 e1082. doi:10.1016/j.ajo.2011.12.012

7. Zhu L, Zha Y, Cai J, Zhang Y. Descemet stripping automated endothelial keratoplasty versus descemet membrane endothelial keratoplasty: a meta-analysis. Int Ophthalmol. 2018;38(2):897-905. doi:10.1007/s10792-017-0533-3

8. Price MO, Giebel AW, Fairchild KM, Price FW Jr. Descemet's membrane endothelial keratoplasty: prospective multicenter study of visual and refractive outcomes and endothelial survival. Ophthalmology. 2009;116(12):2361-2368. doi:10.1016/j.ophtha.2009.07.010

9. Guerra FP, Anshu A, Price MO, Price FW. Endothelial keratoplasty: fellow eyes comparison of Descemet stripping automated endothelial keratoplasty and Descemet membrane endothelial keratoplasty. Cornea. 2011;30(12):1382-1386.

10. Chamberlain W, Lin CC, Austin A, et al. Descemet endothelial thickness comparison trial: a randomized trial comparing ultrathin Descemet stripping automated endothelial keratoplasty with Descemet membrane endothelial keratoplasty. Ophthalmology. 2019;126(1):19-26. doi:10.1016/j.ophtha.2018.05.019

11. Pavlovic I, Shajari M, Herrmann E, Schmack I, Lencova A, Kohnen T. Meta-analysis of postoperative outcome parameters comparing Descemet membrane endothelial keratoplasty versus Descemet stripping automated endothelial keratoplasty. Cornea. 2017;36(12):1445-1451. doi:10.1097/ICO.0000000000001384
12. Phillips PM, Phillips LJ, Muthappan V, Maloney CM, Carver CN. Experienced DSAEK Surgeon's transition to DMEK: outcomes comparing the last 100 DSAEK surgeries with the first 100 DMEK surgeries exclusively using previously published techniques. Cornea. 2017;36(3):275-279. doi:10.1097/ICO.0000000000001069

13. Singh A, Zarei-Ghanavati M, Avadhanam V, Liu C. Systematic review and meta-analysis of clinical outcomes of Descemet membrane endothelial keratoplasty versus Descemet stripping endothelial keratoplasty/ Descemet stripping automated endothelial keratoplasty. Cornea. 2017;36(11):1437-1443. doi:10.1097/ICO.0000000000001320

14. Stuart AJ, Romano V, Virgili G, Shortt AJ. Descemet's membrane endothelial keratoplasty (DMEK) versus Descemet's stripping automated endothelial keratoplasty (DSAEK) for corneal endothelial failure. Cochrane Database Systematic Rev. 2018;6.

15. Schrittenlocher S, Bachmann B, Tiurbe A, et al. Impact of preoperative visual acuity on Descemet Membrane Endothelial Keratoplasty (DMEK) outcome. Graefe's Arch Clin Exp Ophthalmol. 2019;257 (2):321-329. doi:10.1007/s00417-018-4193-4

16. Morishige N, Sonoda K-H. Bullous keratopathy as a progressive disease: evidence from clinical and laboratory imaging studies. Cornea. 2013;32:S77-S83. doi:10.1097/ICO.0b013e3182a1bc65

17. Morishige N, Yamada N, Morita Y, Kimura K, Sonoda K-H. Persistence of structural changes at the anterior cornea in bullous keratopathy patients after endothelial keratoplasty. PLoS One. 2013;8 (9):e74279. doi:10.1371/journal.pone.0074279

18. Claesson M, Armitage W, Fagerholm P, Stenevi U. Visual outcome in corneal grafts: a preliminary analysis of the Swedish Corneal Transplant Register. British J Ophthalmol. 2002;86(2):174-180. doi:10.1136/ bjo.86.2.174

19. Terry MA, Shamie N, Chen ES, et al. Endothelial keratoplasty for Fuchs' dystrophy with cataract: complications and clinical results with the new triple procedure. Ophthalmology. 2009;116(4):631-639. doi:10.1016/j. ophtha.2008.11.004

20. Maier P, Reinhard T, Cursiefen C. Descemet stripping endothelial keratoplasty - rapid recovery of visual acuity. Deutsches Ärzteblatt Int. 2013;110(21):365. doi:10.3238/arztebl.2013.0365

21. Terry MA, Shamie N, Chen ES, Hoar KL, Friend DJ. Endothelial keratoplasty a simplified technique to minimize graft dislocation, iatrogenic graft failure, and pupillary block. Ophthalmology. 2008;115(7):1179-1186. doi:10.1016/j.ophtha.2007.09.005

22. Guell JL, Morral M, Gris O, Elies D, Manero F. Comparison of sulfur hexafluoride $20 \%$ versus air tamponade in Descemet membrane endothelial keratoplasty. Ophthalmology. 2015;122(9):1757-1764. doi:10.1016/j.ophtha.2015.05.013

23. Lee DA, Wilson MR, Yoshizumi MO, Hall M. The ocular effects of gases when injected into the anterior chamber of rabbit eyes. Arch Ophthalmol. 1991;109(4):571-575. doi:10.1001/archopht.1991.01080040139045

24. Peraza-Nieves J, Baydoun L, Dapena I, et al. Two-year clinical outcome of 500 consecutive cases undergoing Descemet membrane endothelial keratoplasty. Cornea. 2017;36(6):655-660. doi:10.1097/ ICO.0000000000001176

25. Quilendrino R, de Mora MR-C, Baydoun L, et al. Prevention and management of Descemet membrane endothelial keratoplasty complications. Cornea. 2017;36(9):1089-1095. doi:10.1097/ICO.0000000000001262

26. Shih CY, Ritterband DC, Rubino S, et al. Visually significant and nonsignificant complications arising from Descemet stripping automated endothelial keratoplasty. Am J Ophthalmol. 2009;148 (6):837-843. doi:10.1016/j.ajo.2009.06.034

27. Heinzelmann S, Böhringer D, Eberwein P, Reinhard T, Maier P. Graft dislocation and graft failure following Descemet membrane endothelial keratoplasty (DMEK) using precut tissue: a retrospective cohort study. Graefe's Arch Clin Exp Ophthalmol. 2017;255(1):127-133. doi:10.1007/ s00417-016-3499-3 


\section{Publish your work in this journal}

Clinical Ophthalmology is an international, peer-reviewed journal covering all subspecialties within ophthalmology. Key topics include: Optometry; Visual science; Pharmacology and drug therapy in eye diseases; Basic Sciences; Primary and Secondary eye care; Patient Safety and Quality of Care Improvements. This journal is indexed on PubMed

Submit your manuscript here: https://www.dovepress.com/clinical-ophthalmology-journal
Central and CAS, and is the official journal of The Society of Clinical Ophthalmology (SCO). The manuscript management system is completely online and includes a very quick and fair peer-review system, which is all easy to use. Visit http://www.dovepress.com/ testimonials.php to read real quotes from published authors. 